\title{
Synthesis and Properties of Segmented Polyurethanes Having Poly(2-oxazoline) Chains
}

\author{
Yasuo Shimano, ${ }^{\dagger}$ Kumiko Sato, Mitsuhide Yoshida, \\ and Shihoko NARUMI \\ Department of Chemical and Biological Engineering, Hachinohe National \\ College of Technology, Tamonoki, Hachinohe 039-1192, Japan
}

(Received December 21, 1998)

KEY WORDS Polyoxazoline/Segmented Polyurethane/Diisocyanate/Diol / Diamine/ Dihydrazide Infrared Spectrum / Contact Angle

The poly(2-alkyl-2-oxazoline)s (PROZO) of poly( $N$ acylethylenimine) (NAEI) structure given by cationic ring-opening polymerization of 2-alkyl-2-oxazoline (ROZO), can be regarded as a polymer homologue of polar aprotic solvents such as $N, N$-dimethylacetamide (DMAc), showing hydrophilic $(\mathrm{R}=\mathrm{Me}, \mathrm{Et})$ or hydrophobic (carbon number of $R \geq 4$ ) properties. ${ }^{1}$ Polymerization of ROZO using bis(oxazolinium) salts ${ }^{2}$ or trans-1,4-dibromo-2-butene (DBB) ${ }^{3}$ as initiators provides living PROZO having propagating species (2oxazolinium salts) on the both ends, which can be hydrolyzed to PROZO-glycols (POG) possessing hydroxyl groups on both polymer ends. ${ }^{3,4}$ For application of the POG, Simionescu and co-workers synthesized macroazo-initiators containing the PROZO chains. ${ }^{5}$

Segmented polyurethanes with alternating sequences of foreign segments exhibit phase separation in soft and hard segments, or hydrophilic and hydrophobic segments. Using these characteristics, various functional polymers such as thermoplastic elastomers, elastic fibers, surface modifier, and medical implants have been realized. Segmented polyurethanes composed of building blocks of PROZO chains are unknown, but should prove usefull materials such as surface modifiers, electrostatic agents, compatibilizers, and antithrombogenic materials. Various types of PROZO have been found applicable for the above materials. ${ }^{6}$ In the present examination, amphiphilic polyurethanes having poly(2-methyl-2oxazoline) (PMeOZO) segments and higher alkylene units were synthesized by reacting ordinary diisocyanates with POG $(\mathrm{R}=\mathrm{Me})$ to form prepolymers having isocyanate groups on both polymer ends, which were chain-extended by polyaddition mainly with dodecanediohydrazide (DDH), 1,10-decanediol (DDO), or 1,10diaminodecane (DAD). In the resulting polyurethanes, the segments based on the diisocyanates and chain extenders (urethane segment) contained hydrophobic and flexible decamethylene chains, while, PMeOZO segments were aprotic and hydrophilic. These polyurethanes can be expected to show characteristic physical properties, i.e., surface nature, crystallinity, and phase separation. This paper describes the synthesis of segmented polyurethanes and properties such as IR spectra, thermal behaviors, and contact angles on the films coated on glass.

\footnotetext{
+ To whom correspondence should be addressed.
}

In blood-compatible polymeric materials, hydrophilic surface depresses the adsorption of blood proteins such as fibrinogen. ${ }^{6 \mathrm{~d} .7}$ Hydrophobic graft chains on the surface increase albumin adsorption to enhance antithrombogeneicity ${ }^{8}$ especially at contact angles of $80-110^{\circ} .{ }^{9}$ Present polyurethanes possessing amphiphilic nature can be expected to make the surface of glass or polymeric materials hydrophilic or hydrophobic by coating or blending, and to show blood-compatibility.

\section{EXPERIMENTAL}

\section{Materials}

$\mathrm{Et}_{2} \mathrm{O}$ were distilled over sodium wire. $\mathrm{CH}_{3} \mathrm{CN}$ was purified by distillation over $\mathrm{P}_{2} \mathrm{O}_{5} . \mathrm{CHCl}_{3}$ and $\mathrm{CH}_{2} \mathrm{Cl}_{2}$ were distilled over molecular sieves. $\mathrm{N}, \mathrm{N}$-dimethylformamide (DMF) and $N$-methyl-2-pyrrolidone (NMP) were distilled over $\mathrm{CaH}_{2}$. 2-Methyl-2-oxazoline (MeOZO), $\mathrm{Et}_{3} \mathrm{~N}$, and triethylenediamine (TDA) were stirred with $\mathrm{KOH}$ and distilled. Methyl tosylate (MeOTs), DBB, 4,4'-methylenebis(phenyl isocyanate) (MDI), 1,6-hexanediisocyanate (HDI), 1,4-butanediol (BDO), DDO, 1,6-diaminohexane (DAH), and DAD were distilled in vacuo. Adipohydrazide (ADH) was recrystallized from ethanol. DDH was prepared by heating di(2-ethylhexyl) dodecanedioate and hydrazine monohydrate in methanol. Dibutyltin dilaurate (DBTL) was used without purification.

\section{Measurements}

${ }^{1} \mathrm{H}$ NMR spectra were recorded by a JEOL JNM LA 400 FT NMR spectrometer with tetramethylsilane as the standard. IR spectra were measured on a JEOL JIR 6000 FT spectrophotometer. GPC measurement was performed using a SHIMADZU LC-10AD chromatograph equipped with a SHIMADZU RID-6A RI detector. For analysis of POG, GPC columns, SHODEX AC-803 and JASCO FINE PACK GEL-101 were connected in series (Column $\mathrm{A}$ ), and $\mathrm{CHCl}_{3}$ was used as the eluent at a flow rate of $0.8 \mathrm{~mL} \mathrm{~min}^{-1}$ with $\mathrm{PMeOZO}$ standard prepared by polymerization of $\mathrm{MeOZO}$ with MeOTs as the initiator. For analysis of polyurethane, two columns of $\mathrm{TOSOH}$ TSKgel $\mathrm{GMH}_{\mathrm{HR}} \mathrm{M}$ were connected in series (Column B), and DMF containing $\mathrm{LiCl}$ was used as eluent $\left(0.8 \mathrm{~mL} \mathrm{~min}^{-1}\right)$ at $60^{\circ} \mathrm{C}$ with polystyrene standard. Differential thermal analysis (DTA), and thermogravi- 
Table I. PMeOZO-glycols $(\mathbf{1}-n)$

\begin{tabular}{|c|c|c|c|c|}
\hline \multirow{2}{*}{$1-n$} & \multicolumn{2}{|c|}{$M_{n}$} & \multirow{2}{*}{$D P_{n}^{\mathrm{a}}$} & \multirow{2}{*}{$M_{w} / M_{n}^{\mathrm{a}}$} \\
\hline & NMR & GPC & & \\
\hline $1-15$ & 1390 & 1370 & 15.1 & 1.07 \\
\hline $1-31$ & 2640 & 2680 & 30.5 & 1.20 \\
\hline
\end{tabular}

a Determined by GPC.

metric analysis (TGA) were performed employing ULVAC TGD 9000. Contact angles were measured on a KYOWA CA-DT contact angle meter for the films sticked on slide glass using polyurethane solutions in NMP.

\section{PMeOZO-Glycol}

POG (1- $n ; n$, degree of polymerization of MeOZO) was prepared as described below. ${ }^{4} \mathrm{MeOZO}$ was polymerized with $\mathrm{DBB}$ as initiator in $\mathrm{CH}_{3} \mathrm{CN}$ at $80^{\circ} \mathrm{C}$ to produce living PMeOZO, whose propagating species (2-oxazolinium salts) on both ends were hydrolyzed by heating with $\mathrm{H}_{2} \mathrm{O}$ and $\mathrm{Na}_{2} \mathrm{CO}_{3}$ in $\mathrm{CH}_{3} \mathrm{CN}$ at $100^{\circ} \mathrm{C}$ giving rise to the 1- $n$ to be listed in Table I. ${ }^{3} M_{n}$ of 1- $n$ was measured by GPC with Column A. $D P_{n}$ calculated from the $M_{n}$ was compatible with the feed ratio of MeOZO to DBB. $M_{n}$ by ${ }^{1} \mathrm{H} \mathrm{NMR}$ in $\mathrm{CDCl}_{3}$ was calculated based on signal integration of $\mathrm{NCH}_{2}$ protons $(\delta 3.30)$ of NAEI unit to $\mathrm{CH}=\mathrm{CH}$ protons $(\delta 5.58)$, being close to the values by GPC. Molecular weight distributions were generally narrow reflected by the living nature of the polymerization.

\section{Synthesis of Segmented Polyurethanes}

As a typical run, the synthesis of MDI/1-15/DDH type polyurethane (Run 1) is described as follows. To a solution of MDI (0.072 g; $0.29 \mathrm{mmol}), \mathrm{Et}_{3} \mathrm{~N}(0.005 \mathrm{~g}$; $0.05 \mathrm{mmol})$, and NMP $(0.04 \mathrm{~mL})$ was dropped a solution of $1-15(0.197 \mathrm{~g} ; 0.14 \mathrm{mmol})$ and NMP $(0.9 \mathrm{~mL})$ for $20 \mathrm{~min}$ at $70^{\circ} \mathrm{C}$ under nitrogen. After $2 \mathrm{~h}$ stirring DDH $(0.037 \mathrm{~g} ; 0.14 \mathrm{mmol})$ was added and stirred for $7 \mathrm{~h}$. The resulting transparent solution was poured into a large amount of $\mathrm{Et}_{2} \mathrm{O}$ and the precipitate formed was purified by reprecipitation using NMP (good solvent) and $\mathrm{Et}_{2} \mathrm{O}$ (poor solvent) to give $0.29 \mathrm{~g}(93 \%)$ of white solid of polyurethane. $M_{n}$ measured by GPC using the Column B was 20300. ${ }^{1} \mathrm{H} \mathrm{NMR}$ (dimethyl sulfoxide (DMSO)- $d_{6}$ ): $\delta 9.53$ (br, $\phi \mathrm{NHCOO}$ and $\phi \mathrm{NHCONN}), 8.58$ (s, $\phi N C O N H N C O), 7.89$ (s, $\phi$ NCONNHCO), 7.24 (d) and $6.98(\mathrm{~d})\left(\mathrm{C}_{6} \mathrm{H}_{4}\right), 5.58(\mathrm{~s}, \mathrm{CH}=\mathrm{CH}), 3.88\left(\mathrm{~s}, \mathrm{CH}_{2}-\mathrm{C}=\mathrm{C}-\right.$ $\left.\mathrm{CH}_{2}\right), 3.77\left(\mathrm{~s}, \phi \mathrm{CH}_{2} \phi\right), 3.34\left(\mathrm{~m}, \mathrm{NCH}_{2}\right), 1.99(\mathrm{~m}$, $\mathrm{CH}_{3} \mathrm{CO}$ ).

\section{RESULTS AND DISCUSSION}

\section{Synthesis of Polyurethanes}

POG 1- $n$ was reacted with double the molecular quantity of diisocyanates in NMP at $70^{\circ} \mathrm{C}$ to form prepolymers (3) having isocyanate groups on both ends, which were extended in situ by diols, diamines, or dihydrazides (4) to give rise to segmented polyurethanes (5) (Scheme 1). Chain extenders 4 had generally decamethylene units more flexible and hydrophobic than us-

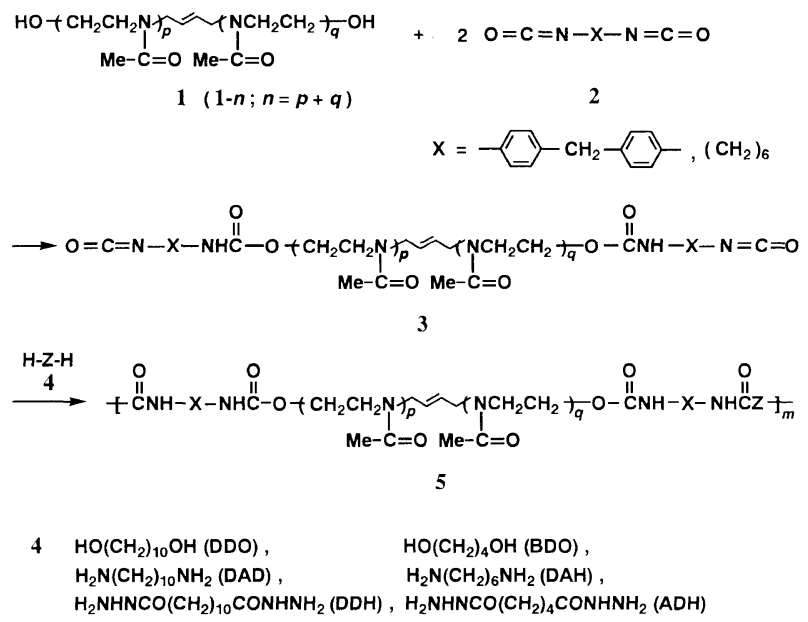

Scheme 1.

ual extenders, e.g., BDO or DAH. For comparison with these extenders, BDO, DAH, and ADH were examined. Polyurethanes $\mathbf{5}$ extended by diamines or dihydrazides are actually poly(urethane-urea)s or poly(urethaneacylsemicarbazide)s, but should be regarded as polyurethanes.

The results of the polymerization based on MDI are shown in Table II. As catalysts for polyadditions, $\mathrm{Et}_{3} \mathrm{~N}$, DBTL, and TDA were examined, and $\mathrm{Et}_{3} \mathrm{~N}$ was found most effective for increasing $M_{n}$ of product polymers. On use of TDA in the 1st stage, gelation was generally observed. DBTL was used in the 2 nd stage with diol extenders in the presence of $\mathrm{Et}_{3} \mathrm{~N}$, but, showed only low effect. GPC curves of the polyurethanes synthesized on a basis of MDI and 1-31 were exhibited with 1-31 in Figure 1. Under the same conditions for polyadditions, chain extender DDH, DAD, and DDO gave the polyurethanes 5 whose $M_{n}$ decreased generally in that order. Dicarboxylic acid dihydrazides are readily reacted with dicarboxylic acid dichlorides without any additives in hexamethylphosphoramide or NMP at room temperature or below to give poly(hydrazide)s of high molar mass. ${ }^{10}$ Carboxylic acid hydrazides can be regarded as nucleophiles having enhanced reactivity by the so-called alpha effect. ${ }^{11}$ Consequently, it may be reasonable to consider aliphatic dicarboxylic acid dihydrazides to be more reactive with diisocyanates than aliphatic diamines in present conditions. The higher reactivity of DAD than DDO is compatible with usual trends for diamines and diols. Molecular weight dispersion $\left(M_{w} / M_{n}\right)$ of 5 was fairly higher than that of feed POG 1- $n$. By HDI as an aliphatic diisocyanate with extenders DDH or DDO, segmented polyurethanes could be produced in the same manner as MDI, but, $M_{n}$ were relatively low compared with those from MDI (Table II). By DAD as the extender in $\mathrm{HDI} / \mathbf{1}-15$ based system at the same reaction condition as the extension by DDH, gelation of the polymerization solution was observed. Polyurethanes 5 obtained from MDI and HDI were generally soluble in NMP, DMF, and DMAc, and partially soluble in $\mathrm{CH}_{3} \mathrm{CN}$ and $\mathrm{MeOH}$, whereas insoluble in $\mathrm{CHCl}_{3}$ and $\mathrm{Et}_{2} \mathrm{O}$.

\section{Properties of Segmented Polyurethanes}

IR Spectra. IR spectra of films of 5 formed on $\mathrm{KBr}$ 
Segmented Polyurethanes Having Poly(2-oxazoline) Chains

Table II. Synthesis of segmented polyurethanes $(\mathbf{5})^{\mathrm{a}}$

\begin{tabular}{|c|c|c|c|c|c|c|c|}
\hline Run & POG & $\begin{array}{l}\text { Diiso- }{ }^{\mathrm{b}} \\
\text { cyanate }\end{array}$ & Extender ${ }^{\mathfrak{c}}$ & $\frac{\text { Yield }}{\%}$ & $M_{n}^{\mathrm{c}}$ & $\frac{T_{\mathrm{d}}^{\mathrm{f}}}{\mathrm{C}}$ & $\begin{array}{c}\text { Contact angle } \\
\text { deg }\end{array}$ \\
\hline 1 & $1-15$ & MDI & $\mathrm{DDH}$ & 93 & 20300 & 197 & 71.2 \\
\hline 2 & $1-31$ & MDI & DDH & 94 & 23600 & 210 & 73.0 \\
\hline 3 & $1-15$ & MDI & DAD & 90 & 18100 & 179 & 87.2 \\
\hline 4 & $1-31$ & MDI & DAD & 93 & 20600 & 181 & 85.1 \\
\hline 5 & 1-15 & MDI & $\mathrm{DDO}^{\mathrm{d}}$ & 93 & 11500 & 195 & 39.5 \\
\hline 6 & $1-31$ & MDI & $\mathrm{DDO}^{\mathrm{d}}$ & 95 & 16800 & 180 & 54.1 \\
\hline 7 & $1-15$ & MDI & $\mathrm{ADH}$ & 90 & 15400 & 176 & 25.6 \\
\hline 8 & $1-31$ & MDI & $\mathrm{ADH}$ & 91 & 18900 & 190 & 34.5 \\
\hline 9 & $1-31$ & MDI & DAH & 94 & 19500 & 183 & 53.2 \\
\hline 10 & $1-31$ & MDI & $\mathrm{BDO}^{\mathrm{d}}$ & 92 & 15700 & 180 & 31.3 \\
\hline 11 & $1-15$ & HDI & $\mathrm{DDH}$ & 94 & 16300 & 196 & 72.4 \\
\hline 12 & $1-31$ & HDI & $\mathrm{DDH}$ & 88 & 18600 & 205 & 75.6 \\
\hline 13 & $1-15$ & HDI & $\mathrm{DDO}^{\mathrm{d}}$ & 93 & 12500 & 178 & 44.1 \\
\hline 14 & $1-31$ & HDI & $\mathrm{DDO}^{\mathrm{d}}$ & 90 & 14700 & 182 & 58.3 \\
\hline
\end{tabular}

${ }^{a}$ In NMP at $70 \mathrm{C}$ in all runs. ${ }^{\mathrm{b}}$ lst stage: [diisocyanate $\left.]_{0} / \mathrm{POG}\right]_{0}=2.0$; catalyst, $\mathrm{Et}_{3} \mathrm{~N}\left(\left[\mathrm{Et}_{3} \mathrm{~N}\right]_{0} /\left[\right.\right.$ diisocyanate $\left._{0}=0.17\right)$; time, $2 \mathrm{~h}$. ${ }^{\mathrm{c}} 2 \mathrm{nd}$ stage: $[\text { extender }]_{0} /[\mathrm{POG}]_{0}=1.0$; time, $7 \mathrm{~h}$. ${ }^{\mathrm{d}} \mathrm{DBTL}$ was added in 2 nd stage with $[\mathrm{DBTL}]_{0} /[\text { extender }]_{0}=0.1$. ${ }^{\mathrm{e}} \mathrm{Measured}$ by GPC using polystyrene standards. 'Decomposition temperature determined by TGA and DTA in air at a heating rate of $10 \mathrm{Cmin}^{-1}$.

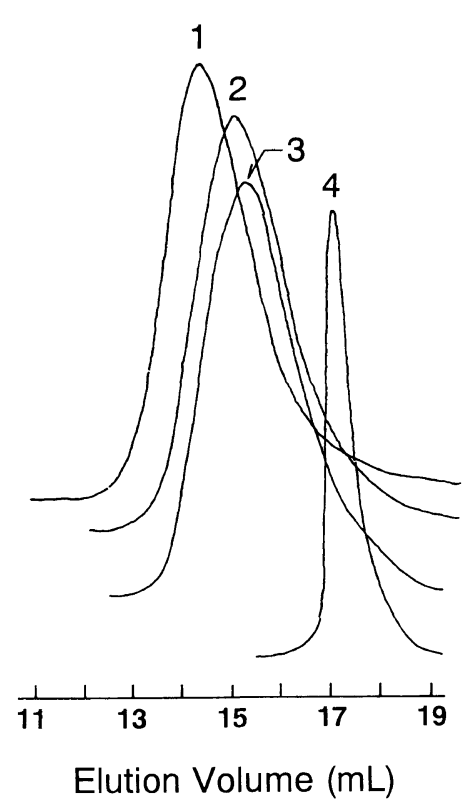

Figure 1. GPC curves of polyurethanes (5) and POG (1-31). 1, Run 2 $\left(M_{w} / M_{n}=1.86\right) ; 2$, Run $4\left(M_{w} / M_{n}=1.84\right) ; 3$, Run $6\left(M_{w} / M_{n}=1.96\right)$; 4, 1-31 $\left(M_{w} / M_{n}=1.20\right)$.

plates were measured as shown in Figure 2. Many examinations of the association states of polyurethanes by hydrogen bonding have been reported. ${ }^{12}$. Lee et al. pointed out with respect to the $\mathrm{MDI} /$ poly(tetramethylene oxide) (PTMO)/BDO polyurethanes that the free $\mathrm{N}-\mathrm{H}$ groups have stretching vibration at $3450 \mathrm{~cm}^{-1}$, and the hydrogen-bonded $\mathrm{N}-\mathrm{H}$ groups have absorption at 3295 or $3330 \mathrm{~cm}^{-1} .^{12 \mathrm{a}}$ In the present work, N-H stretching vibration of MDI/1-15/DDO polyurethane (5; Run 5) is found at 3477 and $3265 \mathrm{~cm}^{-1}$, which were close to the above frequencies for free and bonded ones, respectively. In the $\mathrm{MDI} / \mathrm{PTMO} / \mathrm{BDO}$ polyurethanes, $\mathrm{C}=\mathrm{O}$ groups of the urethane bond show stretching vibration at 1732 and $1703 \mathrm{~cm}^{-1}$ due to free and hydrogen-bonded groups. ${ }^{12 \mathrm{a}}$ The $1726 \mathrm{~cm}^{-1}$ component in 5 of Run 5 can be assigned for stretching vibration of free $\mathrm{C}=\mathrm{O}$ groups of urethane bonds. The stretching absorption of bonded

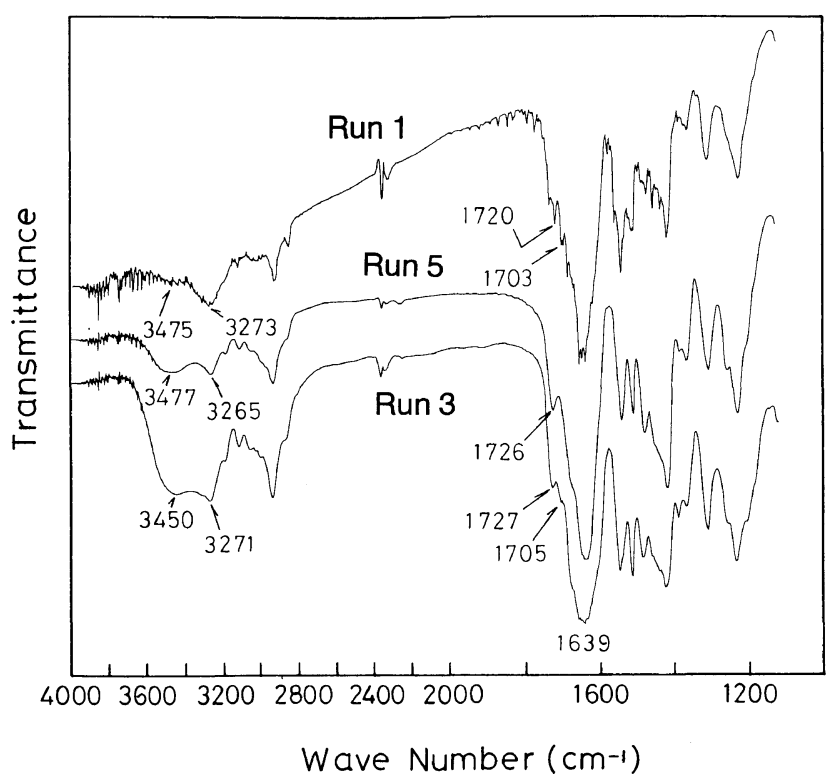

Figure 2. IR spectra of polyurethanes (5): Run 1, MDI/1-15/DDH; Run 3. MDI/1-15/DAD; Run 5, MDI/1-15/DDO.

$\mathrm{C}=\mathrm{O}$ groups cannot be observed, probably because it is included in the strong absorption centered at 1645 $\mathrm{cm}^{-1}$ for $\mathrm{C}=\mathrm{O}$ groups of NAEI units in PMeOZO segments. $\mathrm{N}-\mathrm{H}$ groups of the polar groups (urethane, acylsemicarbazide, and urea) may associate more or less also with $\mathrm{C}=\mathrm{O}$ groups of the NAEI units by hydrogen bonding. In a MDI/1-15/DAD polyurethane (5; Run 3 ), the component around $3450 \mathrm{~cm}^{-1}$ is assignable to stretching vibration of free $\mathrm{N}-\mathrm{H}$ groups of urethane and urea bonds, and a component centered at $3270 \mathrm{~cm}^{-1}$ is due to bonded $\mathrm{N}-\mathrm{H}$ groups. Carbonyl groups of urethane bonds in the Run 3 polymer have stretching absorptions at 1727 and $1705 \mathrm{~cm}^{-1}$ due to free and bonded ones. Stretching vibrations of free and bonded N-H groups of a MDI/1-15/DDH polyurethane (5; Run 1) are centered at 3475 and $3272 \mathrm{~cm}^{-1}$. The latter absorption is much stronger than the former indicating that most of the $\mathrm{N}-\mathrm{H}$ groups are associated with $\mathrm{C}=\mathrm{O}$ groups. For $\mathrm{C}=\mathrm{O}$ groups of urethane bonds in Run 1 polymer, stretching 


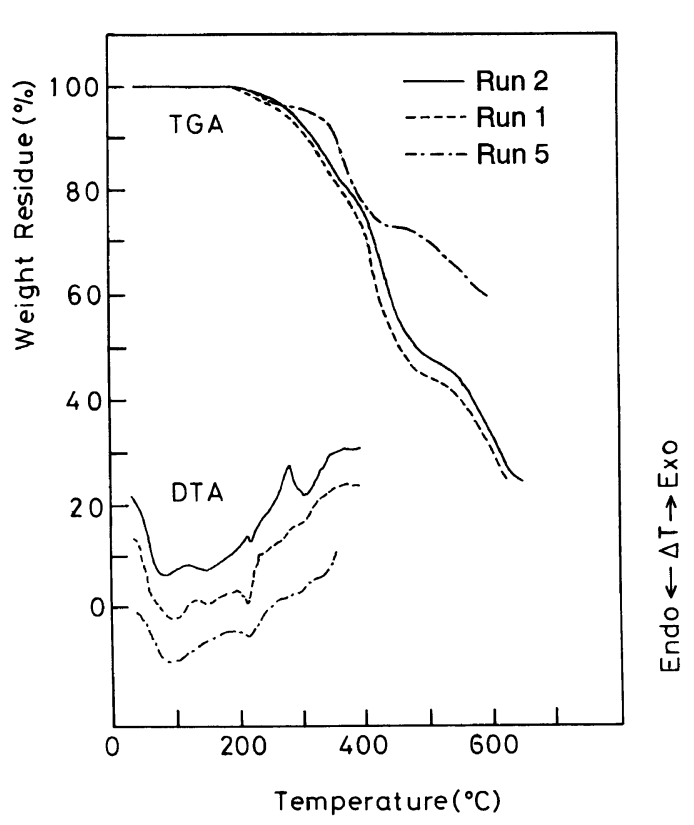

Figure 3. DTA and TGA curves of polyurethanes (5) at a heating rate of $10 \mathrm{Cmin}^{-1}$ under nitrogen: Run 1, MDI/1-15/DDH; Run 2, MDI/1-31/DDH; Run 5, MDI/1-15/DDO.

absorptions of free and bonded ones are observed at 1720 and $1703 \mathrm{~cm}^{-1}$. In conclusion, this polyurethane seems to contain most associated structures in three kinds of polyurethanes, due to two carbonyl groups in an acylsemicarbazide group to increase the number of hydrogen bonds compared to other extending groups (Run 1, 3, and. 5).

Thermal Behavior. TGA and DTA of the polyurethanes $\mathbf{5}$ were carried out in air as shown in Figure 3 and Table II. Exotherm in DTA of the Run 5 polyurethane at $195^{\circ} \mathrm{C}$ is close to the onset of weight loss in TGA, based on thermal decomposition of urethane bond. In wholly urethane-bonded polyurethanes, thermal degradation is known to be initiated with dissociation of urethane bond at around $200^{\circ} \mathrm{C}$ giving back the isocyanate and hydroxy functions. ${ }^{13}$ The poly(urethaneurea)s 5 (Run 3, 4, and 9) showed exotherm at 179 $183^{\circ} \mathrm{C}$, ascribable to dissociation of urethane bonds, not to depolymerization of urea bonds which appear at $300^{\circ}$ C. ${ }^{14}$ The polyurethanes 5 extended by DDH showed higher decomposition temperatures, i.e., $196-210^{\circ} \mathrm{C}$, based on similar behavior of urethane bonds, than those by DDO and DAD, probably due to higher polarity of acylsemicarbazide bonds compared to other extending groups. Acylsemicarbazide bonds are partly similar to hydrazide bonds of poly(hydrazide)s formed via polycondensation of dicarboxylic acid chlorides with dihydrazides. The hydrazide bonds are thermally dehydrated at around $250^{\circ} \mathrm{C}$ with ring closure. ${ }^{10}$ The polyurethanes 5 extended by DDH have the possibility of cyclization by dehydration, but, such behavior could not be observed by DTA and TGA.

Contact Angle. Contact angles of air side of polyurethane films coated on glass are listed in Table II. Decamethylene segments in present amphiphilic polyurethanes $\mathbf{5}$ would make the surface of glass hydrophobic by coating. Hydrophilic and aprotic PMeOZO is known to have affinity with glass. ${ }^{15}$ Contact angles of present polyurethanes 5 thus measured were all higher than that of POG (1-31) $\left(22.0^{\circ}\right)$, therefore, hydrophobic segments seem to migrate more or less to surface (air side). Polyurethanes 5 extended by the DAD, DDH, and DDO showed the contact angles to decrease in that order. The difference in angles by the extenders should be due to polar groups on both sides of the $\left(\mathrm{CH}_{2}\right)_{10}$ segments. The $\left(\mathrm{CH}_{2}\right)_{10}$ segments should migrate to air side via intermolecular phase separation from PMeOZO segments. Basicity of urethane, acylsemicarbazide, and urea groups in the film-casting mixtures should increase in that order, and hence, the affinity of those groups with aprotic PMeOZO segments seems to decrease in that order. Decrease in the affinity should increase the phase separation to promote aggregation of the $\left(\mathrm{CH}_{2}\right)_{10}$ segments on the air sides resulting in increase in contact angles. Increase in the affinity should promote migration of PMeOZO segments with the $\left(\mathrm{CH}_{2}\right)_{10}$ segments to the surface to decrease the contact angles. Although each polyurethanes 5 have urethane bonds, the types of extension groups seem to affect the association of polymer chains. The average deviations of the contact angles measured at ten points were, for examples, \pm 0.2 for Run $2, \pm 0.5^{\circ}$ for Run 4 , and $\pm 0.3^{\circ}$ for Run 6 , being generally slight. Consequently, the influence of macroscopic unevenness of the surfaces can be taken as low. The polyurethanes 5 extended by DAH, ADH, and BDO containing shorter alkylene groups exhibited lower contact angles compared with DAD, DDH, and DDOderived polyurethanes, respectively, probably due to increased influence of hydrophilic PMeOZO segments. Contact angles of HDI-derived polyurethanes (5) should be higher than those of MDI-derived ones, however, the differences were slight.

Thus, novel type amphiphilic polyurethanes were synthesized via chain extension of prepolymers having hydrophilic PMeOZO segments by hydrophobic extenders, i.e., DDH, DAD, and DDO. The product polymers showed intermolecular phase separation (between hydrophilic and hydrophobic segments) on glass, and probability of controlling free surface energy of glass by coating.

\section{REFERENCES}

1. (a) S. Kobayashi and T. Saegusa, in "Ring-Opening Polymerization," K. Ivin and T. Saegusa Ed., Elsevier Applied Science Publishers, Essex, England, 1984, p 764. (b) S. Kobayashi, Prog. Pollm. Sci., 15, 751 (1990). (c) H. Uyama and S. Kobayashi, in "Catalysis in Precision Polymerization," S. Kobayashi Fd., John Wiley \& Sons, Inc. Chichester, 1997, p 399

2. S. Kobayashi, T. Igarashi, Y. Moriuchi, and T. Sacgusa, Macromolecules, 19, 535 (1986).

3. S. Kobayashi, H. Uyama, Y. Narita, and J. Ishiyama, Macromolecules, 25, 3232 (1992).

4. S. Kobayashi, E. Masuda, S. Shoda, and Y. Shimano, Macromolecules, 22, 2878 (1989).

5. C. I. Simionescu, G. David, A. Ioanid, V. Paraschiv, G. Riess, and B. C. Simionescu, J. Polym. Sci., Part A, Polym. Chem., 32, 3123 (1994).

6. (a) I. Yilgor, R. S. Ward, and J. R. Riffle, Polym. Prepr., 28, 369 (1987). (b) M. Miyamoto, Y. Sano, and T. Saegusa, Eur. Polym. J., 19, 955 (1983). (c) S. Kobayashi, M. Kaku, and T. Saegusa, Macromolecules, 21, 334 (1988). (d) M. Kaku, L. C. Grimminger, D. Y. Sogah, and S. L. Haynie, J. Polym. Sci., Part A, Polym. Chem., 32, 2187 (1994). 
7. (a) Y. Mori, S. Nagaoka, H. Takiuchi, T. Kikuchi, N. Noguchi, H. Tanzawa. and Y. Noishiki, Trans. Am. Soc. Artif. Int. Organs, 28, 459 (1982). (b) A. S. Chawla, in "Polymeric Biomaterials," E. Piskin Ed., 1986. (c) K. D. Park, T. Okano, C. Nojiri, and S. W. Kim, J. Biomed. Mater. Res., 22, 977 (1988). (d) K. Fujimoto, H. Tadokoro, M. Minato, and Y. Ikada, Polym. Mater. Sci. Eng., 62, $736(1990)$.

8. (a) M. S. Munro, A. J. Quattrone, S. R. Ellsworth, P. Kulkarni, and R. C. Eberhart, Trans. Am. Soc. Artif. Int. Organs, 27, 499 (1981). (b) M. S. Munro, R. C. Eberhart, N. J. Maki, B. E. Brink, and W. J. Fly, Am. Soc. Artif. Intern. Organs J., 6, 65 (1983). (c) T. G. Grasel, J. A. Pierce, and S. L. Cooper, J. Biomed. Mater. Res., 21, 815 (1987).

9. M. Kober and B. Wesslén, J. Polym. Sci., Part A, Polym. Chem., 30, 1061 (1992).

10. A. H. Frazer and F. T. Wallenberger, J. Polym. Sci., Part A, 2 , 1137 (1964)

11. J. O. Edwards and R. G. Pearson, J. Am. Chem. Soc., 84, 16 (1962).
12. (a) M. M. Coleman, K. H. Lee, D. J. Skrovanek, and P. C. Painter, Macromolecules, 19, 2149 (1986). (b) D. J. Skrovanek, S. E. Howe, P. C. Painter, and M. M. Coleman, Macromolecules, 18, 1676 (1985). (c) R. W. Seymour and S. L. Cooper, Macromolecules, 6, 48 (1973). (d) J. C. West and S. L. Cooper, J. Polym. Sci., Polym. Symp., No. 60, 127 (1977). (e) W. J. MacKnight and M. Yang, J. Polym. Sci., Polym. Symp., No. 42, 817 (1973). (f) C. P. Christenson, M. A. Harthcock, M. D. Meadows, H. L. Spell, W. L. Howard, M. W. Creswick, R. E. Guerra, and R. B. Turner, J. Polym. Sci.-Phys., 24, 1401 (1986).

13. S. Boufi, M. N. Belgacem, J. Quillerou, and A. Gandini, Macromolecules, 26, 6706 (1993).

14. J. M. Richards, W. H. McClennen, H. L. C. Meuzelaar, D. E. Gregonis, W. M. Reichert, and M. A. Helle, Macromolecules, 18 , 496 (1985)

15. S. Shoda, E. Masuda, M. Furukawa, and S. Kobayashi, J. Polym. Sci., Part A, Polym. Chem., 30, 1489 (1992). 